\title{
Budaya Populer dan Estetika Baru melalui Pesona Make Up dan Kostum dalam Film Asterix at the Olympic Games*
}

\author{
Sandi Tramiaji Junior ${ }^{1}$, Autar Abdillah ${ }^{2}$, Trisakti $^{3}$ \\ Pascasarjana Pendidikan Seni Budaya, Universitas Negeri Surabaya \\ doi $10.15408 /$ sjsbs.v7i9.15640
}

\begin{abstract}
This study wants to discuss the new aesthetic or queer aesthetic in the charm of makeup and costumes used in the film Asterix At The Olympic Games by director Frederick Forestier produced in 2008. The perspective taken in this study is charm through makeup and costumes, and its relevance to popular culture and people's interest in fantasy films. This study uses a qualitative method, with film studies as an approach in the analysis of cinematographic studies. Film studies in this study focus on social practice performances about the body, identity, representation, and elements contained in the charm of makeup and costumes in the film Asterix At The Olympic Games. The results showed that Asterix at The Olympic Games became a fantasy film genre that gave the complexity of the show as entertainment. In Asterix at The Olympic Games, there is a parody with an imitation of the situation and culture of Greece, which is conveyed through makeup, costumes, and performances. Alfred Gell, in his study of technology of enchantment, concerned the 'technical complexity' aspects of a work to attract the attention of the audience through the management of makeup and costumes. Furthermore, the concept of theatrical mimicry and parody as a 'technical complexity' is shown as a display of aesthetic queer for the sake of performance that can attract attention because of its shape as a popular culture product that is different for the audience.
\end{abstract}

Keywords: New Aesthetics; The Enchantment Of Makeup And Costumes; Asterix At The Olympic Games

\begin{abstract}
Abstrak
Penelitian ini ingin membahas tentang estetika baru atau queer aesthetic dalam pesona make up dan kostum yang digunakan dalam film Asterix At The Olympic Games karya sutradara Frederick Forestier yang diproduksi tahun 2008. Sudut pandang yang diambil dalam penelitian ini adalah pesona melalui make up dan kostum, dan relevansinya terhadap budaya populer dan minat masyarakat terhadap film fantasi. Penelitian ini menggunakan metode kualitatif, dengan film studies sebagai pendekatan dalam analisis kajian sinematografinya. Film studies dalam penelitian ini berfokus pada pertunjukan praktik sosial mengenai ketubuhan, identitas, representasi, dan unsur-unsur yang terkandung dalam pesona make up dan kostum dalam film Asterix At The Olympic Games. Hasil penelitian menunjukkan Asterix at The Olympic Games menjadi genre film fantasi yang memberikan kompleksitas pertunjukan sebagai hiburan. Di dalam Asterix at The Olympic Games terdapat parodi
\end{abstract}

* Received: April 17, 2020, Revised: July 12, 2020, Published September 3, 2020.

${ }^{1}$ Sandi Tramiaji Junior merupakan pemerhati pertunjukan dan sedang fokus pada riset tentang kompleksitas film. Secara kulutral, Sandi merupakan warga Pascasarjana Pendidikan Seni Budaya, Universitas Negeri Surabaya. E-mail: sanditramiajijunior@yahoo.com

${ }^{2}$ Autar Abdillah merupakan dosen senior di Pascasarjana Pendidikan Seni Budaya, Universitas Negeri Surabaya.

${ }^{3}$ Trisakti merupakan ilmuan yang fokus pada seni pertunjukan, khususnya drama, tari, dan musik. Trisakti juga merupakan dosen senior di Pascasarjana Pendidikan Seni Budaya, Universitas Negeri Surabaya. 


\begin{abstract}
dengan imitasi terhadap situasi dan budaya Yunani yang disampaikan melalui make up, kostum, dan pertunjukannya. Alfred Gell dalam telaahnya mengenai technology of enchantment mementingkan aspek 'kerumitan teknik' dalam suatu karya untuk menarik perhatian penonton melalui pengelolaan make up dan kostum. Lebih lanjut, konsep theatrical mimicry dan parodi sebagai suatu 'kerumitan teknik' ditunjukkan sebagai suatu display atas queer aesthetic untuk kepentingan pertunjukan yang mampu menarik perhatian karena bentuknya sebagai produk budaya populer yang berbeda bagi penonton.

Kata kunci: Estetika Baru; Pesona Make Up Dan Kostum; Asterix At The Olympic Games
\end{abstract}

\title{
A. PENDAHULUAN
}

Film adalah suatu bentuk seni pertunjukan yang beraspek utama musik, komedi, tari, drama, dan aspek pertunjukan lainnya ${ }^{4}$. Film merupakan salah satu jenis karya seni media rekam dan media hiburan yang banyak diminati ${ }^{5}$. Film dibagi menjadi tiga jenis, yaitu jenis film yang pertama adalah film dokumenter, film yang kedua adalah eksperimental atau abstrak, dan yang ketiga adalah film fiksi ${ }^{6}$. Film fiksi banyak digandrungi oleh kalangan, baik fiksi ilmiah dongeng maupun legenda. Kekuatan dari penciptaan film fiksi adalah mampu menghipnotis penonton dan membuat penonton menghadapi rasa percaya terhadap cerita yang kadang-kadang mereka tahu bahwasanya karakter fiksi tidak ada dalam realitas keseharian mereka ${ }^{7}$. Karya fiksi sendiri merupakan hasil karya tutur yang memiliki nilai kepura-puraan dan dinyatakan dalam kalimat yang membentuk narasi ${ }^{8}$.

Di dalam film terdapat unsur pendukung, yang salah satunya adalah make up dan kostum yang merupakan hasil dari unsur seni rupa. Make up yang merupakan sebuah seni melukis wajah dengan bahan dan alat kosmetik berfungsi untuk membentuk watak dan karakter dari seorang aktor. Sedangkan kostum yang merupakan sandangan dan perlengkapannya yang dikenakan pentas berfungsi untuk menunjukkan karakter kondisi sosial dan asal usul aktor tersebut. Kedua unsur tersebut memiliki pesona dalam memikat perhatian penonton. Hal tersebut sesuai dengan pernyataan bahwa pesona dalam film dan seni pertunjukan memiliki fokus pada unsur make up dan kostum, di mana keduanya mampu memberikan daya tarik maksimal dalam sebuah pertunjukan'.

\footnotetext{
${ }^{4}$ Ilham Zoebazary, Kamus Istilah Televisi Dan Film (Jakarta: Gramedia Pustaka Utama, 2010).

${ }_{5}$ Ibid.; Julie Grossman, Adaptation in Visual Culture, Adaptation in Visual Culture (New York: Palgrave Macmillan, 2017).

${ }^{6}$ Zoebazary, Kamus Istilah Televisi Dan Film; E Michael Foster and Stephanie Watkins, "The Value of Reanalysis: TV Viewing and Attention Problems," Child Development 81, no. 1 (2010): 368-375, https://doi.org/10.1111/j.1467-8624.2009.01400.x.

7 Revi Dwiyanti and Agus Suherman, “Unsur Budaya Dalam Cerita Film Cakra Buana Karya Sutradara Massimo Burhanuddin," Lokabasa-Journal of Language Studies, Literature, and Culture Regions and His teachings 10, no. 2 (2019): 204-213; Bill Ivey, "Values and Value in Folklore," Journal of American Folklore 124, no. 491 (2011): 6-18.

${ }^{8}$ Grossman, Adapt. Vis. Cult.; Ivey, "Values and Value in Folklore."

9 Sally M. Gardner, "Uses of the Sampur in the Halus (Refined) Style of Yogyakarta Court Dance," Asian Theatre Journal 32, no. 1 (2015): 228-244; Luca Tateo, “The Dialogical Dance: Self, Identity Construction, Positioning and Embodiment in Tango Dancers," Integrative Psychological and Behavioral Science 48, no. 3
} 
Salah satu film yang menghabiskan dana besar dalam pembuatannya adalah Asterix At The Olympic Games karya sutradara Frederick Forestier yang diproduksi tahun 2008. Film tersebut menjadi film termahal di Eropa pada abad 21 yang menghabiskan biaya $€$ 78.000.000 atau IDR 1.186.795.350.000 (Kurs Mei 2020). Film ini diangkat dari komik karya Goscinny dan Uderzo album ke-12. Menurut laporan yang ditulis pada surat kabar, film ini menghabiskan sebagian besar pengeluarannya untuk keperluan make up dan $\operatorname{kostum}^{10}$. Forestier sebagai sutradara menganggap dua hal tersebut merupakan unsur terpenting dalam membuat cerita fiksi mendapatkan apresiasi fantasi oleh penontonnya.

Berdasarkan penjabaran di atas, penelitian ini ingin membahas tentang pesona make up dan kostum yang digunakan dalam film Asterix At The Olympic Games karya sutradara Frederick Forestier yang diproduksi tahun 2008. Sudut pandang yang diambil adalah pesona melalui make up dan kostum, dan relevansinya terhadap budaya populer dan minat masyarakat terhadap film fantasi.

\section{B. LANDASAN TEORI}

Pemaparan tentang teori film dan teknik pesona oleh Gell akan diawali dengan kaitan antara film dengan budaya populer. Budaya populer merupakan sebuah kekuatan dinamis, yang menghancurkan batasan kuno, tradisi, selera dan mengaburkan segala macam perbedaan ${ }^{11}$. Budaya populer atau budaya massa membaurkan dan mencampur adukkan segala sesuatu, menghasilkan apa yang disebut sebagai budaya homogen ${ }^{12}$. Film Asterix At The Olympic Games memadu-padankan situasi yang saling tarik menarik antara realitas kesejarahan dan fantasi, dengan balutan budaya popular kekinian untuk menarik minat penonton. Selain itu, penonton akan mengalami kedekatan realitas ketika menonton fil Asterix At The Olympic Games.

Terdapat sekumpulan oposisi yang mengatakan tentang budaya seni tinggi melingkupi unsur maskulinitas, produksi, kerja, kecerdasan, sifat aktif, menulis, sedangkan budaya massa atau populer melingkupi feminitas, konsumsi, santai, emosi, sifat pasif, dan membaca ${ }^{13}$. Hal tersebut terdapat pada film Asterix At The Olympic Games yang merepresentasikan kekuasaan gender yang diperkuat dengan make up dan kostum yang digunakan tokoh-tokoh di dalamnya.

(2014): 299-321; Alfred Gell, “Technology of Enchantment and Enchantment of Technology," in The Art of Antrophology Essay and Diagrams, ed. Eric Hirsch (London: Athlone Press, 2006).

${ }^{10}$ Foster and Watkins, "The Value of Reanalysis: TV Viewing and Attention Problems"; Susan

Schuyler, "Reality Television, Melodrama, and the Great Recession," Studies in Popular Culture 37, no. 2 (2015): 43-65.

${ }^{11}$ Schuyler, "Reality Television, Melodrama, and the Great Recession"; John Storey, Cultural Studies Dan Kajian Budaya Pop (Yogyakarta: Jalasutra, 2006).

${ }^{12}$ Jon Kraszewski, "Hybridity, History, and the Identity of the Television Studies Teacher," Cinema Journal 50, no. 4 (2011): 166-172.

13 Judith Lynne Hanna, “Dance and Sexuality: Many Moves," Journal of Sex Research 47, no. 2-3 (2010): 212-241; Marjan Groot, "Crossing the Borderlines and Moving the Boundaries: 'High' Arts and Crafts, Cross-Culturalism, Folk Art and Gender," Journal of Design History 19, no. 2 (2016): 121-136. 
Budaya populer dihasilkan dalam kondisi-kondisi subordinat. Praktik-praktik budaya populer dicirikan oleh kreativitas kaum lemah dalam menggunakan sumber daya yang dihasilkan oleh sistem yang tidak memberdayakan meskipun akhirnya menolak untuk tunduk kepada kekuasaan tersebut ${ }^{14}$. Asterix At The Olympic Games merupakan bentuk produk budaya populer masa kini. Hal tersebut dilihat dari kategorisasi maupun ciri praktik budaya populer sebagai salah satu produk seni dalam budaya populer masyarakat pada masanya ${ }^{15}$.

Asterix At The Olympic Games yang menghabiskan memfokuskan pembuatannya pada make up dan kostum dapat dikatakan sebagai bentuk ekspresi estetis secara emosional sebagai pengalihan kesadaran logika atas realitas, sehingga hal tersebut tepat disampaikan melalui sudut pandang fantasi ${ }^{16}$. Pengungkapan ekspresi estetis ini diiringi dengan penyuguhan akting, gerak atau penampilan di atas panggung pementasan, dalam hal ini adalah pemroduksian film Asterix At The Olympic Games.

Penilaian estetis atas suatu pertunjukan berbeda antara satu orang dengan yang lain. Pemahaman estetis tentang film fantasi dipengaruhi atas budaya yang membentuknya dan selanjutnya menyatu dalam budaya sebagai sebuah pemahaman estetis $^{17}$. Konsep estetis kini tidak lagi diidentikkan dengan keindahan ${ }^{18}$. Perdebatan mengenai nilai estetis make up dan kostum para pemain film Asterix At The Olympic Games dipandang tidak sejalan dengan konsep estetik yang mengusung keindahan sebagai barometernya, sehingga estetika dalam Asterix At The Olympic Games merupakan bentuk estetika baru dalam budaya popular. Oleh karenanya, penelitian ini menggunakan teori budaya populer dan pesona dalam membedah estetika baru yang ada dalam kecenderungan make up dan kostum di film Asterix At The Olympic Games.

\section{METODE PENELITIAN}

Penelitian ini menggunakan metode kualitatif, yaitu metode yang menggunakan data yang berupa uraian kalimat tertulis ataupun lisan dari suatu objek yang bertujuan untuk menggunakan hal-hal yang berhubungan dengan keadaan suatu gejala ${ }^{19}$.

${ }^{14}$ Storey, Cultural Studies Dan Kajian Budaya Pop; Rama J. Joshi, "High Performance Culture," Indian Journal of Industrial Relations 37, no. Developing a Culture of High Performance (2011): 18-30; Grossman, Adapt. Vis. Cult.

15 John Fiske, Pengantar Ilmu Komunikasi (Jakarta: Rajagrafindo Persada, 2012); Schuyler, “Reality Television, Melodrama, and the Great Recession"; Storey, Cultural Studies Dan Kajian Budaya Pop; Rachmah Ida, Studi Media Dan Kajian Budaya (Jakarta: Prenada Media Group, 2014).

${ }^{16}$ Maxine Sheets-Johnstone, "From Movement to Dance," Phenomenology and the Cognitive Sciences 11, no. 1 (2012): 39-57; John Dewey, Art as Experience (New York: Perigee Books, 1980).

17 Tateo, “The Dialogical Dance: Self, Identity Construction, Positioning and Embodiment in Tango Dancers"; I Made Rianta, Hendra Santosa, and I Ketut Sariada, "Estetika Gerak Tari Rejang Sakral Lanang Di Desa Mayong, Seririt, Buleleng, Bali," Mudra Jurnal Seni Budaya 34, no. 3 (2019): 285-393.

${ }^{18}$ Cavid Carr, "Dance Education, Skill, and Behavioral Objectives," The Journal of Aesthetic Education 18, no. 4 (2014): 67-76.

19 Particia Leavy, Research Design: Quantitative, Qualitative, Mixed Methods, Arts-Based, and Community-Based Participatory Research Approaches (New York: The Guilford Press, 2017), http://www.ghbook.ir/index.php?name=فرهنگ نوين\&option=com_dbook\&task=readonline\&book_id=13650\&page=73\&chkhashk=ED9C9491B4\&Itemid=21 
Pemaparan hasil analisis Asterix At The Olympic Games berbentuk deskriptif berupa uraian-uraian secara detail tentang estetika baru yang ada dalam kecenderungan make up dan kostum di film Asterix At The Olympic Games. Pemilihan film Asterix At The Olympic Games sebagai objek penelitian karena peneliti melihat tidak ada pergantian make up dan kostum pada tokoh utama pada film ini yaitu Asterix dan Obelix mulai dari awal cerita hingga akhir cerita. Sehingga, memberikan gambaran tentang pesona tunggal yang ada di dalam make up dan kostum dalam film ini.

Pendekatan yang digunakan dalam penelitian ini adalah film studies untuk mengkaji pesona yang bersifat kekinian secara lebih spesifik sehingga menunjukkan perbedaan dengan ilmu budaya pada umumnya ${ }^{20}$. Film studies merupakan analisis kajian sinematografi yang luas dari sebuah praktik sosial yaitu mengarah para ketubuhan, identitas, representasi, dan unsur-unsur yang ada di dalamnya ${ }^{21}$. Penulis membatasi penelitian ini pada aspek pesona dalam make up dan kostum yang akan mengarahkan sudut pandang pada penemuan estetika baru dalam film yang ada dalam kecenderungan make up dan kostum tokoh utamanya yaitu Asterix dan Obelix di film Asterix at The Olympic Games. Melalui pendekatan ini, diupayakan untuk dapat melihat Asterix at The Olympic Games sebagai sebuah seni pertunjukan masa kini yang di dalamnya terdapat estetika baru berdasarkan kompleksitas unsur pertunjukan dan mampu menganalisisnya dengan didukung teori pesona dan budaya populer sebagai perspektifnya.

Melihat unsur yang terkandung dalam Asterix at The Olympic Games, maka metode kualitatif sesuai digunakan untuk menjawab permasalahan penelitian. Data yang didapatkan selanjutnya akan dianalisis menggunakan model analisis Milles \& Huberman hingga dapat ditarik kesimpulan dan proses akhir adalah disajikan dalam bentuk data deskriptif22.

\section{ANALISIS DAN PEMBAHASAN}

Film ini bercerita tentang seorang pemuda kota Galia yang benama Alafolix mencintai seorang putri dari Yunani bernama Putri Irina ${ }^{23}$. Namun kisah cinta mereka

8\&lang=fa\&tmpl=component; Norman K. Denzin and Yvonna S. Lincoln, eds., The SAGE Handbook of Qualitative Research, Fifth Edit. (Los Angeles: Sage Publications, 2018); Howard Lune and Bruce L. Berg, Qualitative Research Methods for the Social Sciences, Ninth edit. (Essex: Pearson, 2017); Asher Shkedi, Introduction to Data Analysis in Qualitative Research (Singapore: Springer International Publishing, 2019); Kathy A. Mills, Big Data for Qualitative Research, Routledge Focus (Oxon: Routledge, 2019).

${ }^{20}$ Gell, "Technology of Enchantment and Enchantment of Technology"; Bruno Bettelheim, The Uses of Enchantment: The Meaning and Importance of Fairy Tales (New York: Vintage, 1997); Laura Weigert, "Performance," Studies in Iconography 33, no. Special Issue Medieval Art History Today-Critical Terms (2013): 61-72; Richard Schechner, Performance Studies: An Introduction (London: Routledge, 2013).

${ }^{21}$ Richard Schechner, Performed Imaginaries (London: Routledge, 2018); Schechner, Performance Studies: An Introduction; Emilio Audissino, Film/Music Analysis: A Film Studies Approach (New York: Palgrave Studies in Audio-Visual Culture Series, 2017).

${ }^{22}$ Sugiyono, Metode Penelitian Kombinasi (Bandung: Alfabeta, 2011); Tjetjep Rohendi Rohidi, Metode Penelitian Seni (Semarang: Cipta Prima Nusantara, 2011); Shkedi, Introduction to Data Analysis in Qualitative Research.

${ }^{23}$ Rene Goscinny, Asterix at the Olympic Games (United States: Orion, 2004). 
tidak berjalan mulus. Seorang putra kaisar Romawi bernama Brutus juga menginginkan Putri Irina untuk menjadi istrinya. Olimpiade yang diselenggarakan empat tahun sekali akan menjadi bukti kesetiaan cinta dari Alafolix. Mengetahui hal tersebut, Brutus tidak pernah berhenti berjuang dengan cara licik nya. Brutus menggunakan 1001 cara untuk memenangkan perlombaan Olimpiade serta menyingkirkan ayahnya sendiri Julius Caesar dari kursi tahtanya. Alefolix yang dibantu oleh Asterix dan Obelix serta ramuan ajaib yang diberi oleh dukun Panoramic mampu memenangkan Olimpiade tersebut dan membuat Brutus kalah.

Asterix dan Obelix merupakan figur ikonik dalam kisah petualangan Asterix. Asterix memiliki karakter yang cerdas meskipun dia memiliki tubuh yang kecil, memiliki kekuatan ketika meminum ramuan dari dukun Panoramik ${ }^{24}$. Obelix merupakan tokoh yang bertubuh besar namun terlihat bodoh. Obelix memiliki kekuatan yang tak tertandingi, karena pada saat bayi dia masuk dalam kuali ramuan dukun Panoramic ${ }^{25}$. Setting latar kota Galia merupakan salah satu bagian dari kerajaan Romawi yang memiliki otonomi daerah sendiri daerah, sekarang disebut daerah Armorik atau Britania kawasan Perancis Utara. Warga Galia dalam cerita film Asterix at The Olympic Games digambarkan sebagai suatu bangsa yang lugu dan apa adanya namun pemberani dan harus siap bertanding di hadapan negara lawan.

Gambar 1. Poster Asterix at The Olympic Games yang dibuat pada tahun 2008

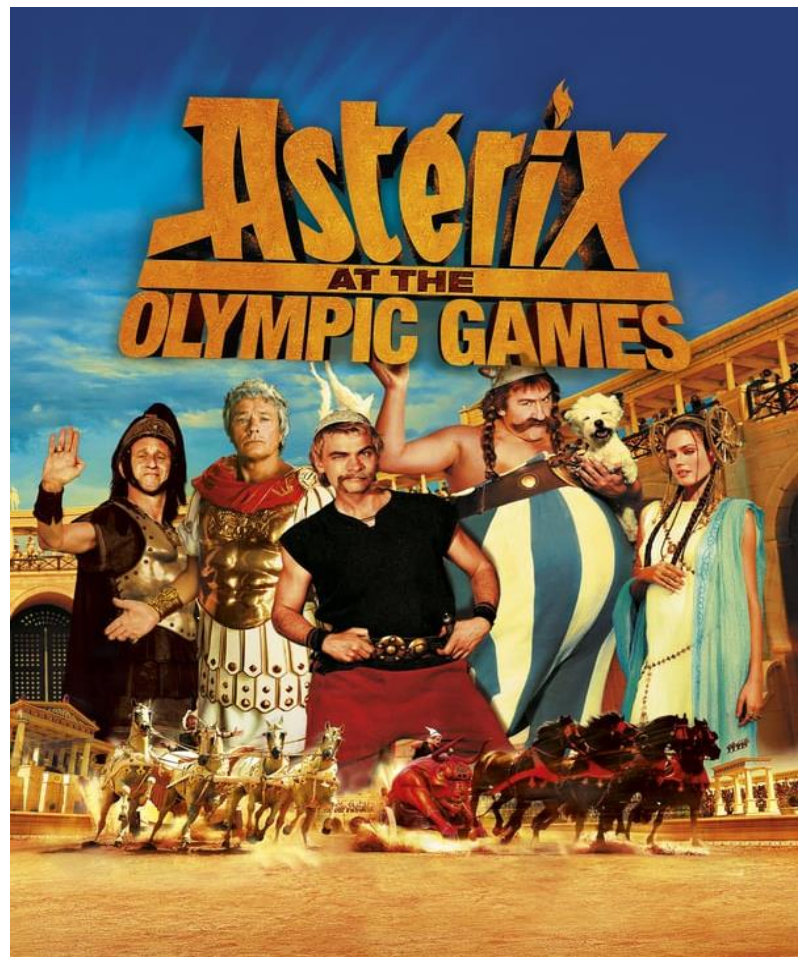

Sumber: https://www.themoviedb.org/movie/2395-ast-rix-aux-jeux-olympiques. ${ }^{26}$

${ }^{24}$ Rene Goscinny, Asterix Obelix and Co. (United States: Orion, 2005).

${ }^{25}$ Ibid.

26 "Asterix at the Olympic Games Poster," accessed April 20, 2020, https://www.themoviedb.org/movie/2395-ast-rix-aux-jeux-olympiques. 
Kostum asterix yang memiliki helm perang yang memiliki sayap burung dan bentuk kostum Obelix yang bewarna belang biru putih dengan celana yang mencapai dada dan telanjang dada digunakan mulai awal cerita hingga akhir cerita ${ }^{27}$. Hal ini terjadi juga pada make up Asterix yang memiliki kumis bewarna emas dan Obelix yang memiliki alis dan rambut warna merah kayu serta hair style yang mengandung simbolsimbol visual.

\section{Gambar 2. Make up dan kostum Asterix dan Obelix pada Asterix at The Olympic Games}

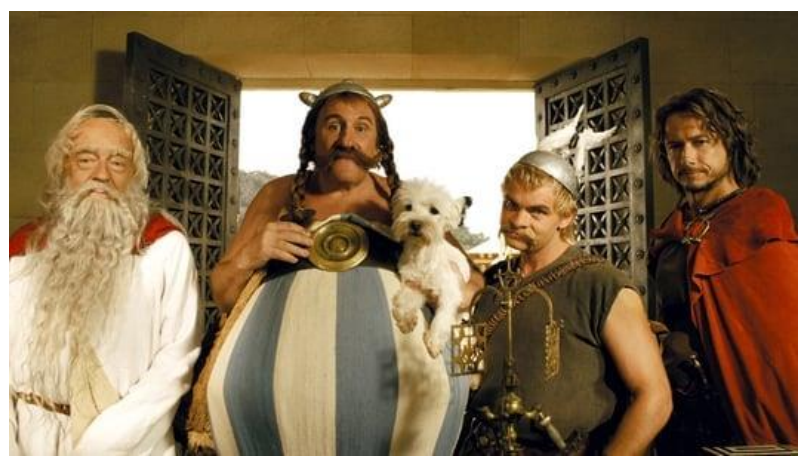

Sumber: https://www.themoviedb.org/movie/2395-ast-rix-aux-jeux-olympiques. ${ }^{28}$

Secara performatif, make up dan kostum yang ditampilkan sebagai identitas Asterix dan Obelix sebagai tokoh utama di Asterix at The Olympic Games terbagi menjadi dua yaitu theatrical mimicry dan parodi ${ }^{29}$. Kedua tokoh utama tersebut melakukan theatrical mimicry sesuai dengan karaktersitik Asterix dan Obelix yang ditirukan. Lebih lanjut, mereka melakukan improvisasi dalam imitasi yang dilakukan dengan konsep parodi. Penyajian Asterix at The Olympic Games bukan merupakan gerak sehari-hari (daily technique), namun lebih kepada kemampuan asterix dan Obelix dalam memproduksi gerak tubuh secara estetis hingga mampu membuat penonton menjadi terpesona. Dalam memunculkan pesona, teknik bukan satu-satunya faktor pendukung. Akan tetapi, extradaily technique menjadi faktor selanjutnya. Sepertihalnya argumentasi yang mengatakan bahwa teknik di luar keseharian, di sisi lain, memberikan informasi, mereka benar-benar menjadikan tubuh dalam bentuk, mengubahnya menjadi buatan/artistik namun dapat percaya $^{30}$.

Indikator lain dari sebuah pesona di luar teknik adalah adanya extra-daily technique sebagai suatu ketidakbiasaan atas kegiatan yang dilakukan sehari-hari ${ }^{31}$. Pada

${ }^{27}$ Goscinny, Asterix at the Olympic Games.

28 "Asterix and Obelix Make Up and Costume," accessed April 21, 2020, https://www.themoviedb.org/movie/2395-ast-rix-aux-jeux-olympiques.

${ }^{29}$ Simon Dentith, Parody: The New Critical Idiom, The New Cr. (London: Routledge, 2002); Linda Hutcheon, A Theory of Parody: The Teachings of Twentieth-Century Art Forms (Los Angeles: University of Illinois Press, 2000).

${ }^{30}$ Henrietta Bannerman, "Is Dance a Language? Movement, Meaning and Communication," Dance Research: The Journal of the Society for Dance Research 32, no. 1 (2014): 65-80; Tamar Jeffers McDonald, Hollywood Catwalk: Exploring Costume and Transformation in American Film (London: I.B. Tauris, 2010); Robert L. Mack, The Genius of Parody: Imitation and Originality in Seventeenth and Eighteenth Century English Literature (United Kingdom: Palgrave Macmillan, 2007).

31 Bettelheim, The Uses of Enchantment: The Meaning and Importance of Fairy Tales; McDonald, Hollywood Catwalk: Exploring Costume and Transformation in American Film. 
Asterix at The Olympic Games, extra-daily technique jelas terlihat mengingat para tokoh di dalamnya melakukan gerak imitasi dan parodi ketika di melakukan penubuhan terhadap tokoh karakter Asterix dan Obelix. Gerak dalam kehidupan Asterix dan Obelix yang dipadu-padankan dengan kesan metaforis yang ada dalam make up mampu memberikan penubuhan dan semakin memberikan daya tarik dalam film ${ }^{32}$. Terdapat istilah mimic gesture dalam analisis make up dan kostum sebagai unsur dalam film dan terbagi menjadi social mimicry, theatrical mimicry dan partial mimicry33. Dalam penampilan Asterix dan Obelix, mereka tergolong dalam theatrical mimicry yang merupakan mimik yang dibuat dari pengelolaan make up dan kostum yang dihasilkan dari sebuah perilaku observasi ${ }^{34}$. Para make up artis di film Asterix at The Olympic Games dengan konsep imitasi melakukan observasi dengan melihat penampilan objek yang ditirukan secara detail baik ekspresi wajah, gaya permainan dalam adegan, cara berjalan, dan hal detail lain dari penampilan objek tersebut. Konsep theatrical mimicry dan parodi dalam Asterix at The Olympic Games bukan hanya menampilkan extra-daily technique, namun juga di luar kebiasaan cerita Asterix at The Olympic Games.

Gell menekankan aspek 'kerumitan teknik' sebagai bagian penting dalam menarik pesona, namun Asterix at The Olympic Games mampu menarik dengan karakteristik yang unik dan berbeda melalui pengelolaan make up dan kostum ${ }^{35}$. Hal ini tentu diiringi dengan suatu teknik tertentu, akan tetapi queer aesthetic sebagai karakter yang kuat membawa pertunjukan ini semakin diminati oleh pengunjung. Queer aesthetic menjadi daya tarik utama sebelum penonton menyaksikan teknik melalui make up dan kostum yang ditampilkan dalam Asterix at The Olympic Games ${ }^{36}$.

Asterix at The Olympic Games dengan queer aesthetic merupakan hal yang baru bagi penonton sehingga mampu mempesona dan menarik perhatian. Lebih jauh, teknik pesona dalam seni mengandung provokasi imajinatif yang sangat tepat diterapkan dalam era disruptif ${ }^{37}$. Ia memberi gambaran melalui karya J.F. Peto's 1894 trompe-l'oeil painting, Old Time Letter Rack, an astonishingly realistic still-life of letters, paper scraps, drawing pins, and faded ribbons ${ }^{38}$. Daya tarik dari karya tersebut adalah ketika penonton

32 Judith L E E Kissell, “Embodiment,” Theoretical Medicine 1, no. 1 (2011): 1-4; Ferdinand Indrajaya, "Art as the Manifestation of Embodiment in the Age of Modern Technology," International Journal of Creative and Arts Studies 5, no. 1 (2018): 1-12.

${ }^{33}$ Mack, The Genius of Parody: Imitation and Originality in Seventeenth and Eighteenth Century English Literature; Jack Curtis Dubowsky, Intersecting Film, Music, and Queerness (New York: Palgrave Studies in Audio-Visual Culture Series, 2016); Audissino, Film/Music Analysis: A Film Studies Approach.

${ }^{34}$ Thomas S. Freeman and David L. Smith, eds., Biography and History in Film (New York: Palgrave Studies in the History of the Media, 2019); Audissino, Film/Music Analysis: A Film Studies Approach.

${ }^{35}$ Gell, "Technology of Enchantment and Enchantment of Technology"; McDonald, Hollywood Catwalk: Exploring Costume and Transformation in American Film.

${ }^{36}$ Dubowsky, Intersecting Film, Music, and Queerness; Robyn Mccallum, Screen Adaptations and the Politics of Childhood Transforming Children's Literature into Film (New York: Palgrave Studies in Audio-Visual Culture Series, 2018), http://www.palgrave.com/gp/series/14654.

37 Gell, "Technology of Enchantment and Enchantment of Technology"; Kassie Kelly and Dana Gorzelany-Mostak, "Teaching the 2016 Campaign through the Art of Parody," American Music 35, no. Music and the Presidential Campaign (2017): 524-530; I Ketut Putu Suardana, "Resolution of Jurnalistic Ethics on Media Disruption Era," Media Bina Ilmiah 21, no. 1 (2020): 1-9.

38 Gell, “Technology of Enchantment and Enchantment of Technology." 
tidak mampu memahami bagaimana cat air mampu membuat sebuah representasi yang realistis, dan dalam Asterix at The Olympic Games dilihat darimake up dan kostum.

Keistimewaan estetis dari make up dan kostum yang digunakan dalam Asterix at The Olympic Games sejatinya melakukan kamuflase dalam pertunjukan yang berbeda dengan penampilan fisik tokoh utamanya dalam kehidupan sehari-hari dalam cerita ${ }^{39}$. Penyampaian imaji yang dilakukan dalam Asterix at The Olympic Games menegosiasikan provokasi imajinatif melalui bentuk yang berbeda. Bukan dalam bentuk yang sulit dipahami, namun melalui queer aesthetic yang ditampilkan di dalam cerita Asterix at The Olympic Games. Make up dan kostum yang digunakan mampu memodifikasi penampilan dan gesture mereka untuk membuat sebuah provokasi visual. Queer aesthetic yang ditampilkan dalam Asterix at The Olympic Games lebih kompleks dari sekedar sebuah konsep pertunjukan. Para pemain dalam Asterix at The Olympic Games tampil sebagai diri mereka yang sesungguhnya, yang telah menubuh dengan tokoh karakter dalam pertunjukan yang dimainkan. Pada akhirnya pertunjukan menampilkan sebuah provokasi imajinatif antara rekayasa dan kenyataan fantasional. Queer aesthetic merupakan bentuk estetika yang lain sehingga dapat menarik banyak penonton sebagai sebuah produk budaya populer ${ }^{40}$. Oleh karenanya, sebagai budaya populer, Asterix at The Olympic Games identik dengan queer aesthetic yang mampu menarik budaya konsumsi penontonnya.

\section{E. KESIMPULAN}

Asterix at The Olympic Games menjadi genre film fantasi yang memberikan kompleksitas pertunjukan sebagai hiburan. Di dalam Asterix at The Olympic Games terdapat parodi dengan imitasi terhadap situasi dan budaya Yunani yang disampaikan melalui make up, kostum, dan pertunjukannya. Alfred Gell dalam telaahnya mengenai technology of enchantment mementingkan aspek 'kerumitan teknik' dalam suatu karya untuk menarik perhatian penonton, dan dalam Asterix at The Olympic Games karya tersebut adalah pengelolaan make up dan kostum yang digunakan di dalamnya. Asterix at The Olympic Games menampilkan perilaku effeminate sebagai bentuk ekspresi estetis dan menggunakan arena film sebagai media untuk berekspresi diri. Kebutuhan akan pertunjukan dan hasrat untuk menampilkan identitas dalam make up dan kostum dinegosiasikan menjadi sebuah pertunjukan spektakuler yang mengusung konsep theatrical mimicry dan parodi sebagai suatu 'kerumitan teknik'. Pemain dalam Asterix at The Olympic Games menampilkan suatu display atas queer aesthetic untuk kepentingan pertunjukan. Korelasi antara ekspresi diri dan ekspresi estetis dikemas menjadi bentuk estetika baru yang menarik penonton. Queer aesthetic mampu menarik perhatian karena

${ }^{39}$ Tristan Samuk, "Satire and the Aesthetic in As You Like It," Renaissance Drama 43, no. 2 (2015): 117-142; Mack, The Genius of Parody: Imitation and Originality in Seventeenth and Eighteenth Century English Literature; McDonald, Hollywood Catwalk: Exploring Costume and Transformation in American Film; Dubowsky, Intersecting Film, Music, and Queerness.

${ }^{40}$ B. Block and J. L. Kissell, "The Dance: Essence of Embodiment," Theoretical Medicine and Bioethics 22, no. 1 (2011): 5-15; Gordon Graham, Philosophy of the Art (London: Routledge, 1997); Dubowsky, Intersecting Film, Music, and Queerness. 
bentuknya yang berbeda bagi penonton dan mampu mengklaim sebagai produk budaya populer yang melahirkan budaya pertunjukan melalui queer aesthetic yang terkandung di dalamnya

\section{REFERENSI}

Audissino, Emilio. Film/Music Analysis: A Film Studies Approach. New York: Palgrave Studies in Audio-Visual Culture Series, 2017.

Bannerman, Henrietta. "Is Dance a Language? Movement, Meaning and Communication." Dance Research: The Journal of the Society for Dance Research 32, no. 1 (2014): 65-80.

Bettelheim, Bruno. The Uses of Enchantment: The Meaning and Importance of Fairy Tales. New York: Vintage, 1997.

Block, B., and J. L. Kissell. “The Dance: Essence of Embodiment.” Theoretical Medicine and Bioethics 22, no. 1 (2011): 5-15.

Carr, Cavid. "Dance Education, Skill, and Behavioral Objectives." The Journal of Aesthetic Education 18, no. 4 (2014): 67-76.

Dentith, Simon. Parody: The New Critical Idiom. The New Cr. London: Routledge, 2002.

Denzin, Norman K., and Yvonna S. Lincoln, eds. The SAGE Handbook of Qualitative Research. Fifth Edit. Los Angeles: Sage Publications, 2018.

Dewey, John. Art as Experience. New York: Perigee Books, 1980.

Dubowsky, Jack Curtis. Intersecting Film, Music, and Queerness. New York: Palgrave Studies in Audio-Visual Culture Series, 2016.

Dwiyanti, Revi, and Agus Suherman. “Unsur Budaya Dalam Cerita Film Cakra Buana Karya Sutradara Massimo Burhanuddin." Lokabasa-Journal of Language Studies, Literature, and Culture Regions and His teachings 10, no. 2 (2019): 204-213.

Fiske, John. Pengantar Ilmu Komunikasi. Jakarta: Rajagrafindo Persada, 2012.

Foster, E Michael, and Stephanie Watkins. "The Value of Reanalysis: TV Viewing and Attention Problems." Child Development 81, no. 1 (2010): 368-375. https://doi.org/10.1111/j.1467-8624.2009.01400.x.

Freeman, Thomas S., and David L. Smith, eds. Biography and History in Film. New York: Palgrave Studies in the History of the Media, 2019.

Gardner, Sally M. "Uses of the Sampur in the Halus (Refined) Style of Yogyakarta Court Dance." Asian Theatre Journal 32, no. 1 (2015): 228-244.

Gell, Alfred. "Technology of Enchantment and Enchantment of Technology." In The Art of Antrophology Essay and Diagrams, edited by Eric Hirsch. London: Athlone Press, 2006.

Goscinny, Rene. Asterix at the Olympic Games. United States: Orion, 2004. 
- - - Asterix Obelix and Co. United States: Orion, 2005.

Graham, Gordon. Philosophy of the Art. London: Routledge, 1997.

Groot, Marjan. "Crossing the Borderlines and Moving the Boundaries: 'High' Arts and Crafts, Cross-Culturalism, Folk Art and Gender." Journal of Design History 19, no. 2 (2016): 121-136.

Grossman, Julie. Adaptation in Visual Culture. Adaptation in Visual Culture. New York: Palgrave Macmillan, 2017.

Hanna, Judith Lynne. "Dance and Sexuality: Many Moves." Journal of Sex Research 47, no. 2-3 (2010): 212-241.

Hutcheon, Linda. A Theory of Parody: The Teachings of Twentieth-Century Art Forms. Los Angeles: University of Illinois Press, 2000.

Ida, Rachmah. Studi Media Dan Kajian Budaya. Jakarta: Prenada Media Group, 2014.

Indrajaya, Ferdinand. "Art as the Manifestation of Embodiment in the Age of Modern Technology." International Journal of Creative and Arts Studies 5, no. 1 (2018): 1-12.

Ivey, Bill. "Values and Value in Folklore." Journal of American Folklore 124, no. 491 (2011): 6-18.

Joshi, Rama J. "High Performance Culture." Indian Journal of Industrial Relations 37, no. Developing a Culture of High Performance (2011): 18-30.

Kelly, Kassie, and Dana Gorzelany-Mostak. "Teaching the 2016 Campaign through the Art of Parody." American Music 35, no. Music and the Presidential Campaign (2017): 524-530.

Kissell, Judith L E E. “Embodiment.” Theoretical Medicine 1, no. 1 (2011): 1-4.

Kraszewski, Jon. "Hybridity, History, and the Identity of the Television Studies Teacher." Cinema Journal 50, no. 4 (2011): 166-172.

Leavy, Particia. Research Design: Quantitative, Qualitative, Mixed Methods, Arts-Based, and Community-Based Participatory Research Approaches. New York: The Guilford

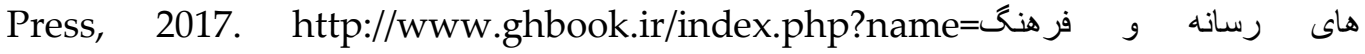
نوين\&option=com_dbook\&task=readonline\&book_id=13650\&page=73\&chkhash k=ED9C9491B4\&Itemid=218\&lang=fa\&tmpl=component.

Lune, Howard, and Bruce L. Berg. Qualitative Research Methods for the Social Sciences. Ninth edit. Essex: Pearson, 2017.

Mack, Robert L. The Genius of Parody: Imitation and Originality in Seventeenth and Eighteenth Century English Literature. United Kingdom: Palgrave Macmillan, 2007.

Mccallum, Robyn. Screen Adaptations and the Politics of Childhood Transforming Children's Literature into Film. New York: Palgrave Studies in Audio-Visual Culture Series, 2018. http://www.palgrave.com/gp/series/14654.

McDonald, Tamar Jeffers. Hollywood Catwalk: Exploring Costume and Transformation in American Film. London: I.B. Tauris, 2010. 
Mills, Kathy A. Big Data for Qualitative Research. Routledge Focus. Oxon: Routledge, 2019.

Rianta, I Made, Hendra Santosa, and I Ketut Sariada. “Estetika Gerak Tari Rejang Sakral Lanang Di Desa Mayong, Seririt, Buleleng, Bali." Mudra Jurnal Seni Budaya 34, no. 3 (2019): 285-393.

Rohidi, Tjetjep Rohendi. Metode Penelitian Seni. Semarang: Cipta Prima Nusantara, 2011.

Samuk, Tristan. "Satire and the Aesthetic in As You Like It." Renaissance Drama 43, no. 2 (2015): 117-142.

Schechner, Richard. Performance Studies: An Introduction. London: Routledge, 2013.

- - - Performed Imaginaries. London: Routledge, 2018.

Schuyler, Susan. "Reality Television, Melodrama, and the Great Recession." Studies in Popular Culture 37, no. 2 (2015): 43-65.

Sheets-Johnstone, Maxine. "From Movement to Dance." Phenomenology and the Cognitive Sciences 11, no. 1 (2012): 39-57.

Shkedi, Asher. Introduction to Data Analysis in Qualitative Research. Singapore: Springer International Publishing, 2019.

Storey, John. Cultural Studies Dan Kajian Budaya Pop. Yogyakarta: Jalasutra, 2006.

Suardana, I Ketut Putu. "Resolution of Jurnalistic Ethics on Media Disruption Era." Media Bina Ilmiah 21, no. 1 (2020): 1-9.

Sugiyono. Metode Penelitian Kombinasi. Bandung: Alfabeta, 2011.

Tateo, Luca. "The Dialogical Dance: Self, Identity Construction, Positioning and Embodiment in Tango Dancers." Integrative Psychological and Behavioral Science 48, no. 3 (2014): 299-321.

Weigert, Laura. "Performance." Studies in Iconography 33, no. Special Issue Medieval Art History Today - Critical Terms (2013): 61-72.

Zoebazary, Ilham. Kamus Istilah Televisi Dan Film. Jakarta: Gramedia Pustaka Utama, 2010.

"Asterix and Obelix Make Up and Costume." Accessed April 21, 2020. https://www.themoviedb.org/movie/2395-ast-rix-aux-jeux-olympiques.

"Asterix at the Olympic Games Poster." Accessed April 20, 2020. https://www.themoviedb.org/movie/2395-ast-rix-aux-jeux-olympiques. 